Min Hang*, Qiren Xiang and Dongxiao Li

\title{
Covering China's New Development Pattern: Issues and Strategies for Transcultural Communication
}

https://doi.org/10.1515/jtc-2021-2006

Published online October 26, 2021

Abstract: The profound integration of China's economy into the global economic and trade system creates an open cultural environment that facilitates cooperation and exchanges between China and the outside world. It is essential to understand how media with diverse cultural backgrounds cover China's new development pattern and how they narrate China's economic development in the global community. This essay examines the above issues from three perspectives: policy narrative, system narrative, and identity narrative. The diverse narratives provide implications for us to understand China's economic policy in the global context, and to pursue new insights into transcultural communication.

Keywords: new development pattern, media coverage, strategic narrative, transcultural communication

\section{Introduction}

The "New development pattern", often referred to as the "dual circulation", was firstly proposed at the meeting of the Standing Committee of the Political Bureau of the CPC Central Committee on May 14, 2020. It was further expounded in the Outline of China's 14th Five-Year Plan (2021-2025) for National Economic and Social Development and the Long-Range Objectives through the Year 2035. The "new development pattern" entails that "in the process of development, China needs to make full use of the advantages of domestic and international markets, with domestic circulation as the main body, while making domestic and international dual circulations promote each other to accelerate China's economic

*Corresponding author: Min Hang, Tsinghua University, Beijing, China,

E-mail: hangmin@tsinghua.edu.cn

Qiren Xiang and Dongxiao Li, Tsinghua University, Beijing, China, E-mail: xqr19@mails.tsinghua.edu.cn (Q. Xiang), tobeachild@126.com (D. Li)

Ә Open Access. @ 2021 Min Hang et al., published by De Gruyter. (co)BY the Creative Commons Attribution 4.0 International License. 
development" (Xinhua, 2020); it is an essential strategic deployment to steer China's future growth in the fast-changing domestic and foreign environment.

As one of the most important social and economic development strategies for China in the next few decades, the call for the "new development pattern" has attracted much attention from the global society, with an increasing media coverage. As the agenda-setting of the global media has direct impact on the attitude and perception of the overseas public (McCombs \& Shaw, 1972), it is important to examine the relevant media coverage in order to understand the portrait and interpretation of this very strategic notion in different social and cultural contexts.

The current study, with an integrated theoretical construct of transcultural communication and strategic narratives, looks into the global media. Descriptive analyses and statistic tests are conducted to observe the differences and similarities of media coverage on the "new development pattern". Based on the rationales of transcultural communication, the policy narrative, system narrative and identity narrative theories are employed. Findings from the study are expected to provide new insights into media and communication practices, as well as China's economic policy communication.

\section{Theoretical Framework}

\subsection{Transcultural Communication}

The concept of transcultural communication is closely linked with the notion of intercultural communication. Intercultural communication studies are the communication process between cultures and how culture influences communication. It seeks to examine the interactions in the communication. In his book, The Silent Language, Hall (1959) proposes the notion of intercultural communication, with which he argues that misunderstandings in communication are related to different cultures.

The study of intercultural communication aims to improve and promote the interaction between groups representing different communication cultures. Scholars suggest that cultural differences may cause miscommunication and even conflicts (Triandis, 2000); Communication is impaired in multicultural environment due to language barriers, lack of trust, lack of experience, differences in values and behavior standards, and lack of understanding of other cultures and stereotypical thinking (Lifintsev \& Canhavilhas, 2017). Thus, the ability to realize cultural differences is requisite to reconciling cultural dilemmas (Glover \& Friedman, 2015). 
A concept developed from intercultural communication is transcultural communication. Welsch (1999) argues that compared with interculturality, the concept of transculturality is considered to be the most appropriate one of cultural today. Pennycook (2006) introduces the concept of transcultural communication to describe "the constant processes of borrowing, bending and blending of cultures, to the communicative practices of people interacting across different linguistic and communicative codes”. Different from intercultural communication's proposition that culture has blurred boundaries, transcultural communication believes that cultural boundaries can be transcended and transgressed. Therefore, a transcultural perspective provides a new start point in intercultural communication (Baker, 2018).

\subsection{Strategic Narrative in the International Relations}

A variety of factors that influence the communication process between cultures have been studied over the years, among which three are major: perception, verbal processes, and nonverbal processes (Samovar \& Porter, 2007). Perception refers to a process in which individuals choose, evaluate, and organize external stimuli, that is internally influenced by the verbal and nonverbal processes from social organizations including family, state, and media (Samovar \& Porter, 2007; Singer, 1987). Global media in culturally dissimilar countries may narrate differently, which are the key verbal processes that affect the perception of people, and further influence the outcome of transcultural communication. In order to examine the verbal process of global media, this study adopts the strategic narrative theory as the analytical framework.

Narrative is a framework that allows human beings to connect seemingly unrelated phenomena around the transformation of causality (Todorov \& Weinstein, 1969). The connection between strategy, narrative and international relationships proposed by Freedman (2006) in his study on how one party in an irregular military conflict utilizes strategic narrative to defeat the other, in which a compelling storyline that describes the event convincingly is essential. He argues that narratives are designed or nurtured with the intention to structure the responses of others to developing events. The theory is applied to further examine the importance of media power in contemporary international relations (De Franco, 2012) and to interpret regional conflicts and the link between policymakers and public opinion (De Graaf, Dimitriu, \& Ringsmose, 2015). Narratives are also reckoned as a strong soft power resource that helps to directly rectify the false impression in the formation, diffusion, and reception of the reported object in the international system (Roselle, Miskimmon, \& O’loughlin, 2014). Nye (2008) 
argues that the dominant manifestation of soft power in international affairs is "who tells a more appealing story", which highlights the global communication as a powerful indication the world system. Thus, a political actor may employ the strategic narrative in the media to influence the international relations. Miskimmon, O'loughlin, and Roselle (2013) illustrated how the strategic narratives are adopted by investigating the Libya crisis starting in 2011. This incident initially brought out the divergence of international public opinions but ultimately effectuated the implementation of a no-fly zone by NATO. The strategic narratives of France and the UK played a key role in forming a consensus among countries involved to accept the 1973 UN resolution.

\subsection{Communication in Strategic Narrative}

Given that the carrier of strategic narrative must be a particular medium, strategic narrative and transcultural communication research are inherently connected. Castells (2009) made an important starting point for the strategic narrative study in the field of communication by emphasizing that political actors must strengthen and highlight certain narratives to achieve their goals in international relations and by offering an approach of how the power relationship works through communication. Moreover, the narratives of news media are proved to be vital in international relations and foreign affairs; as a third party, it plays a vital role in conveying information to parties involved in the affairs through news reports (Arno \& Dissanayake, 2019). Media narratives of global news organizations play a significant role in policymakers' decision-making process and eventually affect the outcomes of events (Gilboa, 2005). Therefore, for communication studies, the strategic narrative is an explanatory tool to build a framework and to construct a shared meaning to the past, present, and future to achieve their political goals (Hellman \& Wagnsson, 2013).

As the country's major social and economic development policy, the "new development pattern" has profound influences inside and outside China, attracting a wide range of global media attention. Hence, the impact of strategic narrative on the global media coverage presents a significant issue for study.

\subsection{Framework of the Strategic Narrative}

To observe the strategic narrative, Miskimmon et al. (2013) developed a theoretical framework, by which they proposed three levels of strategic narrative: issue narrative, system narrative, and national narrative to identify issues of communication in 
international relations and to analyze how a country, as the narrative subject, explains its propositions of the world order, the core of its development concept, and the government policies to the outside world. Specifically, the system narrative examines the political actors in the world system and explain how the world is structured, who the players are and how the system works. The national narrative clarifies the story of a country and what values and goals it adheres to. The issue narrative focuses on interpreting the policy itself and on elaborating why a policy is produced and how successfully it is implemented.

For the study of a specific issue, such as a country's policy with an international influence, the strategic narratives are set on three levels: system narrative, identity narrative and policy narrative. The system narrative describes the structure of the international system; the identity narrative presents the country's political actors' identity, values, and goals, whereas the policy narratives explain the motivation of policymaking and the approach to implement it successfully. These three levels are inextricably linked internally (Miskimmon, O’loughlin, \& Roselle, 2017).

\subsection{Questions Raised for the Research}

Based on the above theoretical framework, the current study categorizes strategic narratives of the "new development pattern" at three levels: system narrative, identity narrative and policy narrative; hence three research questions are proposed:

1. At the three levels of strategic narrative, how do global media understand and interpret the "new development pattern"?

2. Among the culturally different countries/regions, are there any differences in the strategic narratives of the media coverage of the "new development pattern"?

3. Based on the analysis of the strategic narratives of the "new development pattern”, what are the implications for transcultural communication?

\section{Methodology}

To conduct such a study, samples of news reports are retrieved from three categories of media outlets: Western media, Chinese mainland media, and the other Asian media (except those in Chinese mainland), based on their status and influences. The three categories are set because of their respective geographic features as well as their culture differences. One distinguishing cultural difference is that the Asian countries and regions, especially China, embrace the cultural tradition (Taoism and 
Confucianism) that harmony is the ultimate good, while the Western culture usually regards transformation as the ultimate good (Ishii, Klopf \& Cooke, 2003).

As for the Western media, Reuters, Consumer News and Business Channel (CNBC), British Broadcasting Corporation (BBC), Financial Times, The Guardian, The New York Times (NYT), and The Washington Post (WP) are selected. For the Chinese mainland media, China Global Television Network (CGTN) and China Daily are selected. And for the other Asian media (except those in Chinese mainland), Nihon Keizai Shimbun (NKS), Asahi Shimbun, The Straits Times, Al Jazeera, and South China Morning Post (SCMP) are chosen.

It is found that the "new development pattern" strategy is covered in diverse forms in different media, with the "new development pattern" and "dual circulation" as the two most frequently used keywords. Therefore, keyword combinations of "new development pattern \& China" and "dual circulation \& China", are adopted to retrieve reports from the aforementioned news websites. The sampling time range is set to cover one year from May 14, 2020 to April 14, 2021, as the concept of "new development pattern" was first introduced on May 14, 2020. After sorting out irrelevant results, a total of 105 valid samples from 14 media organizations are collected, among which 26 articles are from the Western media outlets, 37 from Chinese mainland media, and 42 from other Asian media organizations. The distribution of the reports is shown in Table 1.

Correlation is found between the geographic/cultural distance from China and the number of reports. For the quantity of reports, among all the Western media outlets, British media produce significantly higher number of articles than their counterparts in the U.S. In Asian regions, media outlets in Chinese Hong Kong, Chinese mainland and Japan produce considerably larger number of reports than the others.

From the chronological order, most coverage of the Western media were reported from September 2020 to October 2020, during the Fifth Plenary Session of

Table 1: Distribution of reports.

\begin{tabular}{lrlrlr}
\hline Western & number & other Asian & number & Chinese mainland & number \\
\hline Reuters & 13 & SCMP & 22 & China Daily & 21 \\
Financial Times & 4 & NKS & 8 & CGTN & 16 \\
CNBC & 3 & Asahi Shimbun & 4 & & \\
The Guardian & 3 & The Straits Times & 4 & & \\
BBC & 1 & Al Jazeera & 4 & & \\
NYT & 1 & & & & 37 \\
WP & 1 & & & & \\
Total & 26 & & 42 & & \\
\hline
\end{tabular}


the 19th CPC Central Committee (Figure 1). By contrast, from August 2020 to March 2021, there are a large number of reports from the Asian media, most of them appeared between October 2020 and March 2021. Moreover, media in Chinese mainland and other Asian countries and regions also cover intensively before and after the annual Two Sessions, namely, the National People's Congress and the Chinese People's Political Consultative Conference. Compared with the Western media outlets, the Asian media are found to be more concerned with China's economic development and policies.

For the analysis of strategic narratives, this essay applies both quantitative and qualitative methods, and the study focuses on media narratives at three levels: policy, system, and identity. Specifically, the policy narrative focuses on the narratives of the attribute of the policy, i.e., do the media organizations position the "new development pattern" policy as an economic policy or a political policy? And the narrative of the policy intention addresses issues such as how the media interpret China's motives for promoting the "new development pattern". For example, who is the beneficiary of the policy? Is it China itself or is there a win-win situation between China and other countries? The level of system narrative focuses on media's narration of the current international system and global order in the context of the "new development pattern". The level of identity narrative focuses on media narrative's positioning of China's identity in the international society (As shown in Figure 2).

12

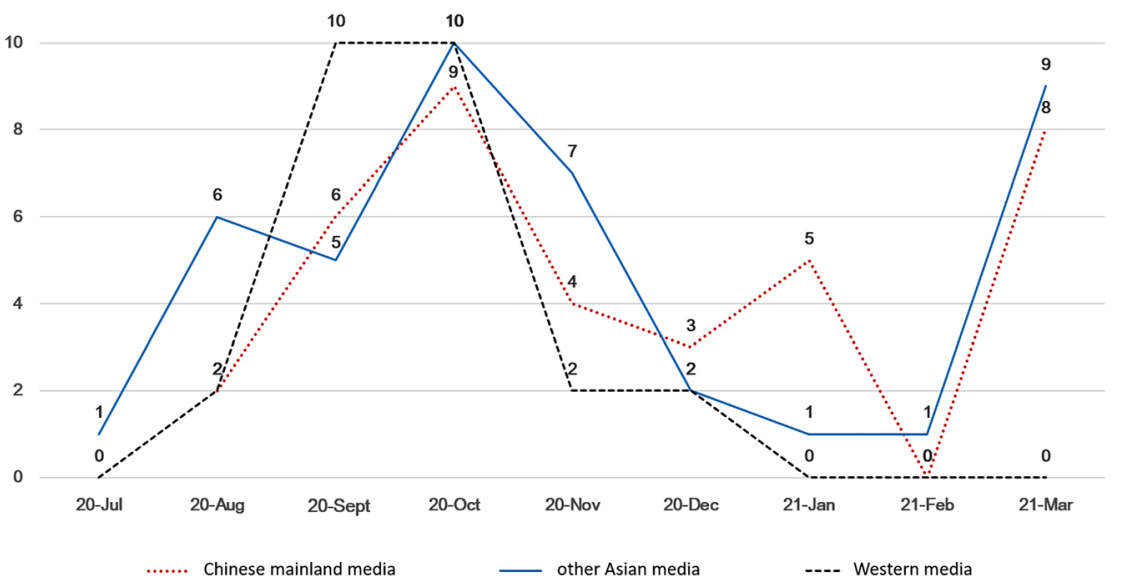

Figure 1: Chronological order of reports. 


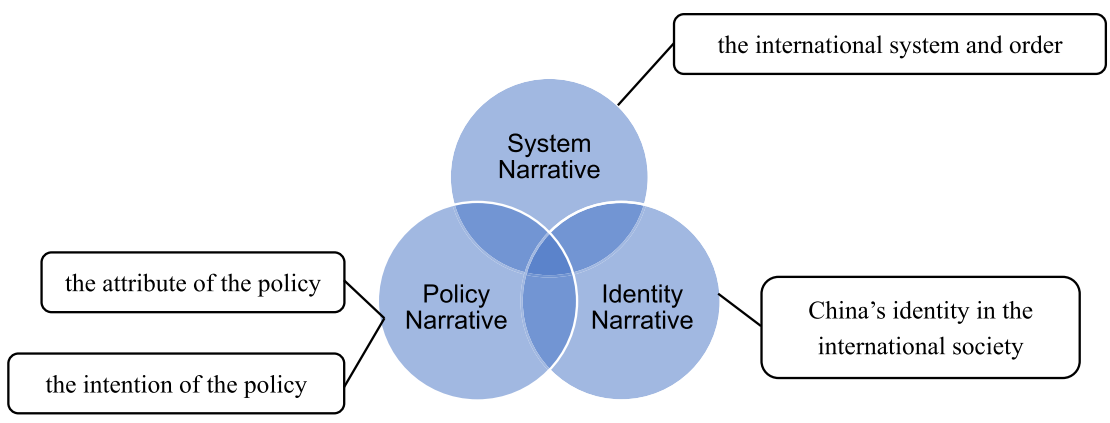

Figure 2: Three levels of strategic narrative on the "new development pattern".

\section{Analysis of the News Coverage}

\subsection{Overall Comparison Between Different Media}

Through observation, it is found that Western media, Chinese mainland and the other Asian media share similarities when covering the "new development pattern". In the narration of the current international community status and the global order, they all interpret the "new development pattern" in a context of high uncertainty. However, while covering the intention and attributes of the "new development pattern" and the identity of China, different media have their respective reporting focuses.

Word clouds are created based on the verbal frequency and relevance, and the main focus of the three types of media as presented, as shown in Figures 3, 4, and 5. It is found that Western and the other Asian media prefer to use the expression of "dual circulation", while Chinese mainland media use both "dual circulation" and "new development pattern". The word "United States" appears more often in Western media, which may imply that Western media tend to create a narrative pattern of Sino-US comparison. In addition, compared with the Chinese mainland media, the other Asian and Western media devote a larger proportion of attention to issues such as economic reliance, internal circulation, and Chinese domestic market consumption, focusing heavily on the challenges China is confronted with while it adopts the "new development pattern" strategy.

\subsection{Analysis of the Policy Narratives}

\subsubsection{Attributes}

Two dimensions are reflected in the narratives of the attributes of the "new development pattern" strategy in the global media. The narratives of economic 


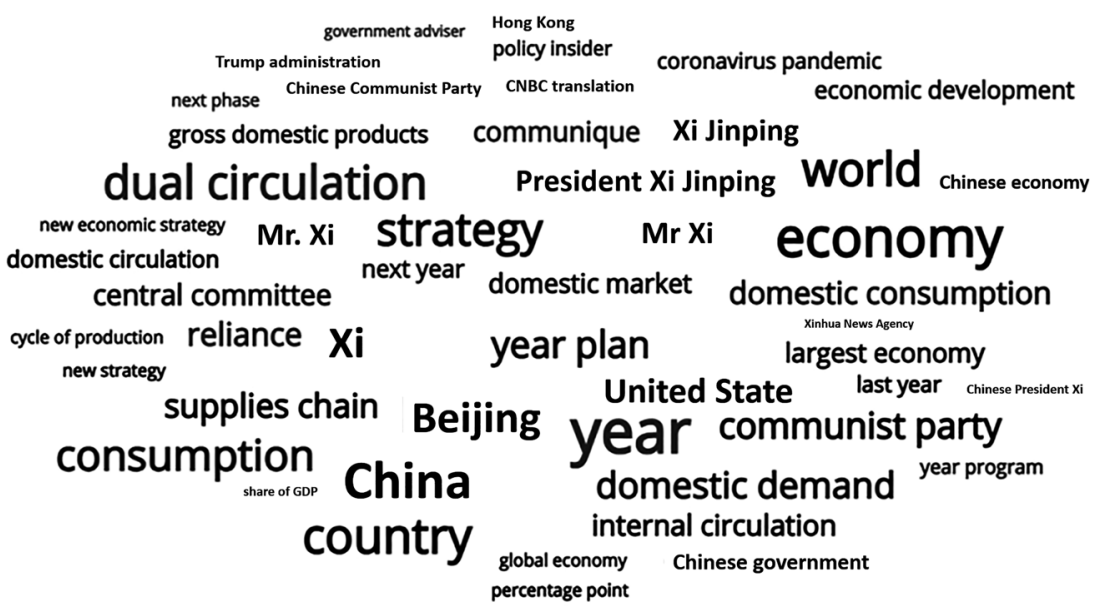

Figure 3: Word cloud of Western media.

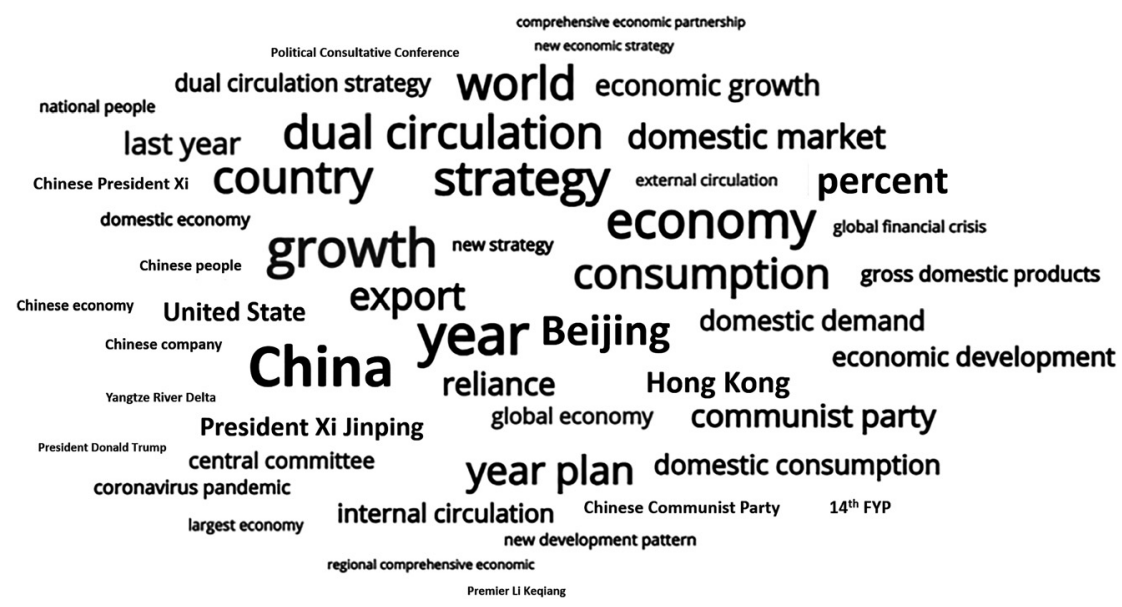

Figure 4: Word cloud of other Asian media.

dimension describe the "new development pattern" as a plan for China's medium and long-term economic development, while the narratives of political dimension seek to interpret it as a strategy with strong political purpose. The coding result (Figure 6) shows that slightly over half of the Western media coverage (54\%) fall into the dimension of political narrative. In contrast, most of the media in the other Asian regions follow the economic narrative dimension (69\%). In addition, nearly 


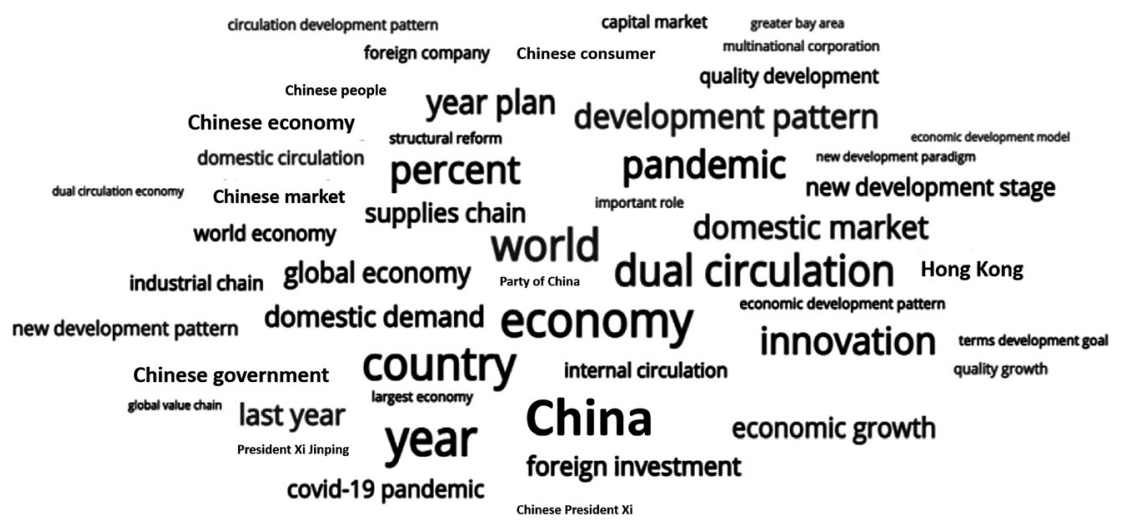

Figure 5: Word cloud of Chinese mainland media.

$90 \%$ of the Chinese mainland media comply with the economic narrative dimension.

A chi-square test is used to examine the differences of the narratives on the policy attributes among the three categories of media. As shown in Table 2, the $\chi^{2}$ value is 13.66 and the statistical significance is $0.001(P<0.05)$, which shows significant differences among the three categories in interpreting the policy attributes of the "new development pattern."

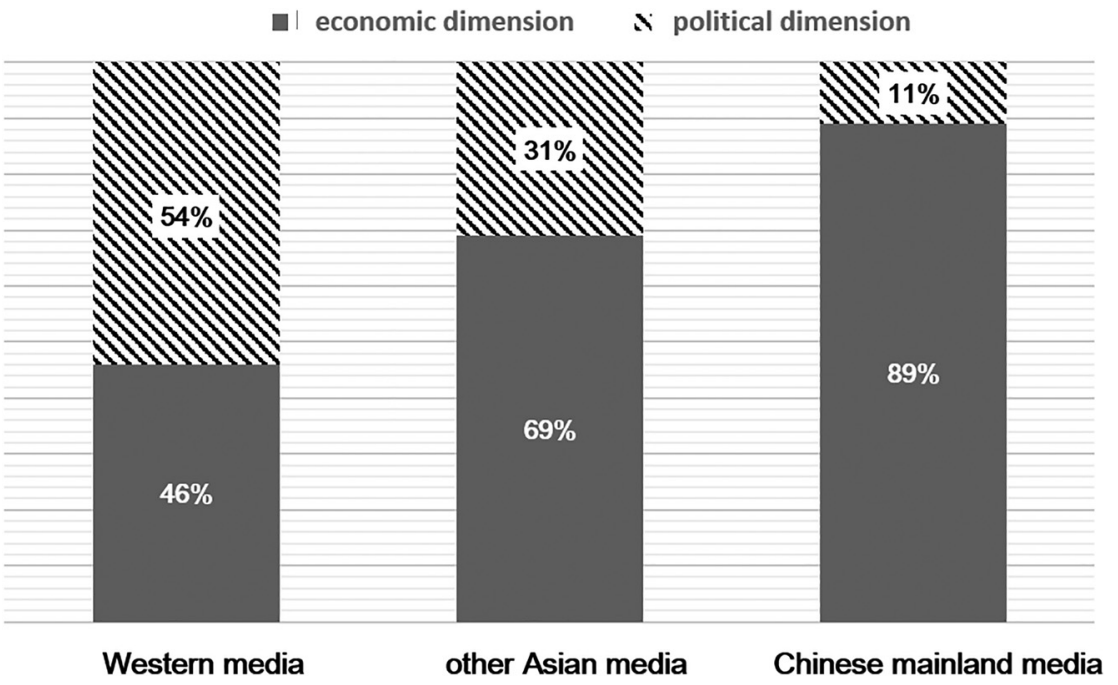

Figure 6: Media narrative of the policy attribute. 
Table 2: Cross tabulations and chi-square test between media type and policy attribute.

\begin{tabular}{|c|c|c|c|c|}
\hline \multicolumn{5}{|c|}{ Policy attribute } \\
\hline- & & Political & Economic & Total \\
\hline \multirow[t]{3}{*}{ Media } & Western & 12 & 14 & 26 \\
\hline & other Asian & 29 & 13 & 42 \\
\hline & Chinese mainland & 33 & 4 & 37 \\
\hline \multicolumn{2}{|l|}{ Total } & 74 & 31 & 105 \\
\hline \multicolumn{3}{|l|}{-} & Value & Statistical significance \\
\hline \multicolumn{3}{|c|}{ Pearson's chi-squared test } & 13.660 & 0.001 \\
\hline \multicolumn{3}{|c|}{ Likelihood ratio } & 14.213 & 0.001 \\
\hline \multicolumn{3}{|c|}{ Linear correlation } & 13.508 & 0.000 \\
\hline \multicolumn{3}{|c|}{ Number of valid cases } & 105 & \\
\hline
\end{tabular}

\subsubsection{Intention}

In terms of policy intention narratives, although the "new development pattern" emphasizes that China will continue to open up and to further promote the external circulation, the narratives of policy intention among the global media are diverging, basically falling into two types: 1 ) erroneous narratives that the strategy is only beneficial to China, where reports only emphasize the significance of the "new development pattern" for China's own development; and 2) narratives that it is beneficial to the development of the world as well as that of China.

Figure 7 shows that most Western media coverage (73\%) only highlights the strategy's benefits to China's development; some Western media even declare that the "new development pattern" would harm the interests of other countries. In contrast, nearly half of the total coverage (48\%) from other Asian media perceives the strategy as a policy benefiting the whole world.

A chi-square test is adopted to observe the differences of the narratives on policy intention between the three categories of media. As shown in table 3, the $\chi^{2}$ value is 24.096 and the statistical significance is $0.000(P<0.05)$, so significant differences are found among the three categories in interpreting the policy intention of the "new development pattern".

While covering the "new development pattern", the Chinese mainland media convey the essentials of the pattern clearly and treat the pattern as an economic policy. It is noted that the "new development pattern" will strengthen the domestic circulation and domestic economy; "highlighting the internal market is by no 


\section{only beneficial to China $s$ beneficial to the world}

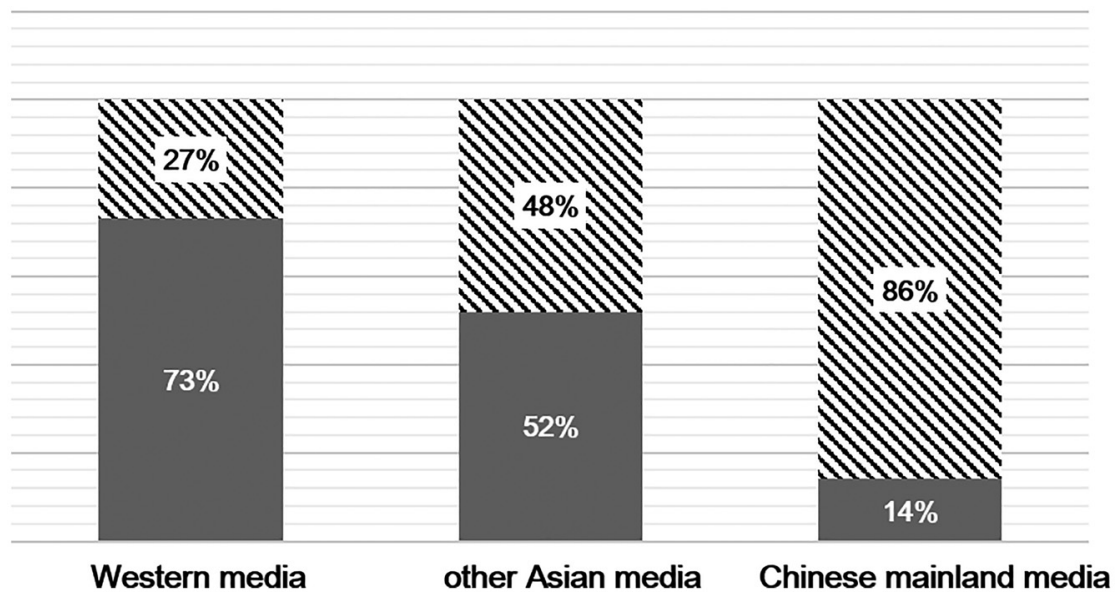

Figure 7: Media narrative of the policy intention.

Table 3: Cross tabulations and chi-square test between media type and policy intention.

\begin{tabular}{|c|c|c|c|c|}
\hline \multicolumn{5}{|c|}{ Policy intention } \\
\hline \multicolumn{2}{|l|}{-} & Type 1 & Type 2 & Total \\
\hline \multirow[t]{3}{*}{ Media type } & Western & 7 & 19 & 26 \\
\hline & other Asian & 20 & 22 & 42 \\
\hline & Chinese mainland & 32 & 5 & 37 \\
\hline \multicolumn{2}{|l|}{ Total } & 74 & 31 & 105 \\
\hline \multicolumn{3}{|l|}{-} & Value & Statistical significance \\
\hline \multicolumn{3}{|c|}{ Pearson's chi-squared test } & 24.096 & 0.000 \\
\hline \multicolumn{3}{|c|}{ Likelihood ratio } & 26.222 & 0.000 \\
\hline \multicolumn{3}{|c|}{ Linear correlation } & 23.040 & 0.000 \\
\hline \multicolumn{3}{|c|}{ Number of valid cases } & 105 & \\
\hline
\end{tabular}

Type 1 - only beneficial to China; Type 2 - beneficial to the world.

means an effort to downgrade opening up. Instead, the pattern aims to promote a higher level of opening up by using both domestic and overseas resources and markets” (CGTN, 2020). Furthermore, “developing China's domestic market will bring huge opportunities for foreign products and services" (CGTN, 2021). In the financial sector, “the opening of China's stock and bond markets gives investors 
access to Chinese companies serving both sectors of the dual economy” (Guppy \& $\mathrm{Xu}, 2020)$.

When the other Asian media are observed, there exist some similarities in interpretation. For example, most coverage from the Singaporean media (75\%) believes that the "new development pattern" strategy is a policy conducive to global cooperation and "Singapore can play a key role in the external part of China's new 'dual circulation' economic strategy, and can be a base for Chinese companies looking to expand into South-East Asia” (Wei, 2021).

The narrative strategy of the Western media is distinct from that of the Chinese mainland and the rest of Asia. Many Western media reports narrate the strategy of the "new development pattern" incorrectly as a policy with political propaganda, and some distort the facts; they rarely regard it as a favorable policy for the global economy. For example, the Washington Post holds the opinion that "China is preparing for a new world order" and "while the world was distracted by the drama of the U.S. presidential election, Xi quietly unveiled an economic strategy fit for a new Cold War" (Tharoor, 2020). The New York Times notes that "China is preparing for an even further degree of decoupling” and "A push for technological independence could further alarm those in the West who have worried that China has turned its back on Deng Xiaoping's era of' 'reform and opening up'" (Buckley, 2020). It is found that the Western media are more concerned about the potential changes in the global power and economic system, which are brought about by the implementation of the strategy of the "new development pattern".

\subsubsection{Analysis of the System Narratives}

The narratives of the international system in the coverage of the "new development pattern" can be divided into five main focuses as shown in Figure 8. The outbreak of COVID-19 has had a tremendous impact on the international political and economic systems, and aggravated the chaos of global political order, economic order and security order; it may also have accelerated the process of de-globalization. In such a background, while covering the "new development pattern", a large proportion of reports from the Western (31\%), Chinese mainland (27\%), and the other Asian media $(43 \%)$ share a common feature: they all take uncertainty as the central theme of the system narrative.

A chi-square test is used to determine the differences of the system narrative of different media. As shown in Table 4, the $\chi^{2}$ value is 33.228 and the statistical significance is $0.000(P<0.05)$, proving significant differences among the three categories of media in the system narrative of the "new development pattern". 


\section{Western media other Asian media $\boxminus$ Chinese mainland media}

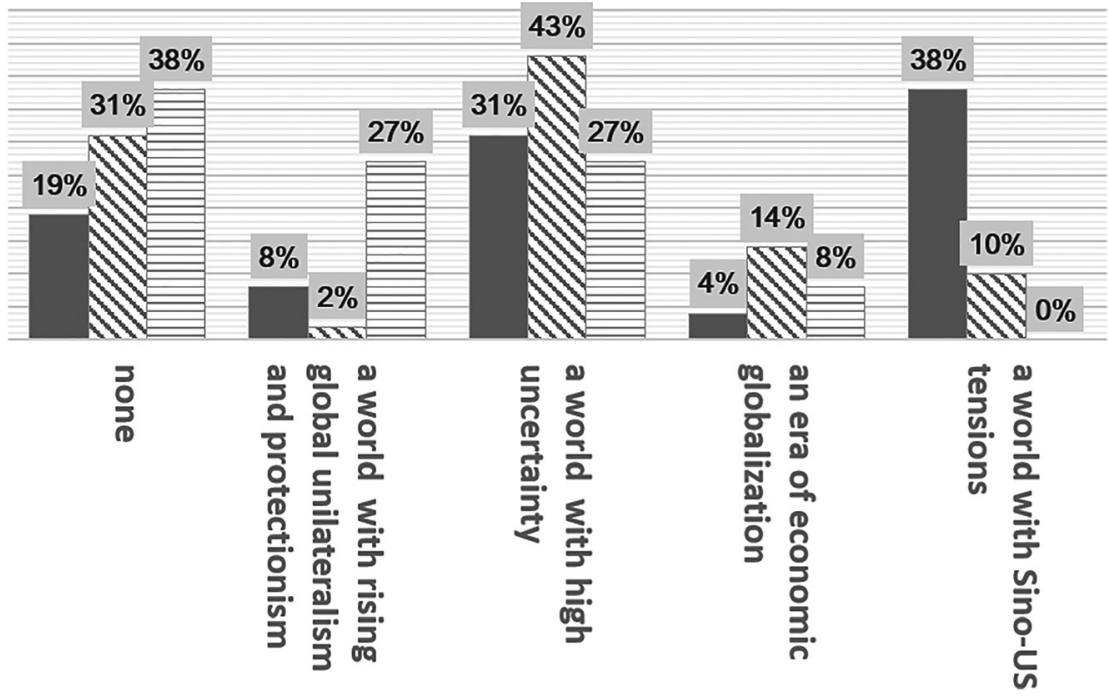

Figure 8: Analysis of the system narratives.

Table 4: Cross tabulations and chi-square test between media type and system narrative.

\begin{tabular}{|c|c|c|c|c|c|c|c|}
\hline \multicolumn{8}{|c|}{ System narrative } \\
\hline- & & Type 1 & Type 2 & Type 3 & Type 4 & Type 5 & Total \\
\hline \multirow[t]{3}{*}{ Media } & Western & 5 & 2 & 8 & 1 & 10 & 26 \\
\hline & other Asian & 13 & 1 & 18 & 6 & 4 & 42 \\
\hline & Chinese mainland & 14 & 10 & 10 & 3 & 0 & 37 \\
\hline \multicolumn{2}{|l|}{ Total } & 32 & 13 & 36 & 10 & 14 & 105 \\
\hline \multicolumn{6}{|l|}{-} & Value & Statistical significance \\
\hline \multicolumn{4}{|c|}{ Pearson's chi-squared test } & & & 33.228 & 0.000 \\
\hline \multicolumn{4}{|c|}{ Likelihood ratio } & & & 34.396 & 0.000 \\
\hline \multicolumn{4}{|c|}{ Linear correlation } & & & 13.916 & 0.000 \\
\hline \multicolumn{4}{|c|}{ Number of valid cases } & & & & 105 \\
\hline
\end{tabular}

Type 1 - none; Type 2 - a world global unilateralism and protectionism rise; Type 3 - a world with high uncertainty; Type 4 - the era of economic globalization; Type 5 - a world with Sino US tensions.

Specifically, narrative strategies vary among Western, Chinese mainland, and the other Asian media. In the system narrative of the other Asian media, the uncertainty of the world is the most prominent focus. For the Chinese mainland 
media, although the tension between China and the United States is mentioned in some reports, it is not the focus of the system narrative. In addition to the uncertainty of the world, another focus of Chinese mainland media's system narrative is the threat and prevalence of global unilateralism and protectionism. On the one hand, "facing protectionism in terms of supply and demand, China will promote dual-circulation, which takes the domestic market as the mainstay. This is a strategic response to protectionism, rather than an act of cutting off China from the outside world and refusing to open up" (Teng, 2020). On the other hand, "dual circulation is a naturally occurring development in many advanced economies; it shouldn't be associated with the superficially similar protectionist trends that sprouted up in the West over the past few years, especially after the global economic crisis brought about by COVID-19. Dual circulation and protectionism are actually two very different visions" (Korybko, 2020).

The differences between Western media and Chinese mainland media on the system narratives demonstrate that the Western media erroneously highlight the tension between China and the United States and its impact on the international order. As written in a Reuters report, "As tensions between Washington and Beijing rise, the potential decoupling of the world's two largest economies presents significant risks, a prospect that is firming China's resolve to shift reliance to its own vast domestic market, policy insiders said" (Yao, 2020). Absurd voices are increasingly heard in the US such as "the pursuit of deep economic integration with China is a strategic mistake", that "it works out extremely well for China, but considerably less well for the US” (Cheng, 2020).

\subsubsection{Analysis of the Identity Narratives}

Studies in the field of international politics suggest that the identity of political actors directly affects their foreign policy. In other words, a country's decisionmaking behavior in the international political arena is closely linked to its identity. Therefore, in this regard, the global media's strategic narratives of the "new development pattern" not only focus on the attribute and intention of policy, but also reflect how they perceive China's identity in the world system. Observing the global media and taking the most prominent identity narrative in the reports into account, we have noticed six typical narratives of the Chinese identity (see from Figure 9).

A chi-square test is performed to find out the differences of the identity narratives among the three categories of media. As shown in Table 5 , the $\chi^{2}$ value is 46.674 and the statistical significance is $0.000(P<0.05)$, which shows significant differences in the identity narratives on the "new development pattern". 


\section{Western media $\triangle$ other Asian media $\quad$ 目 Chinese mainland media}

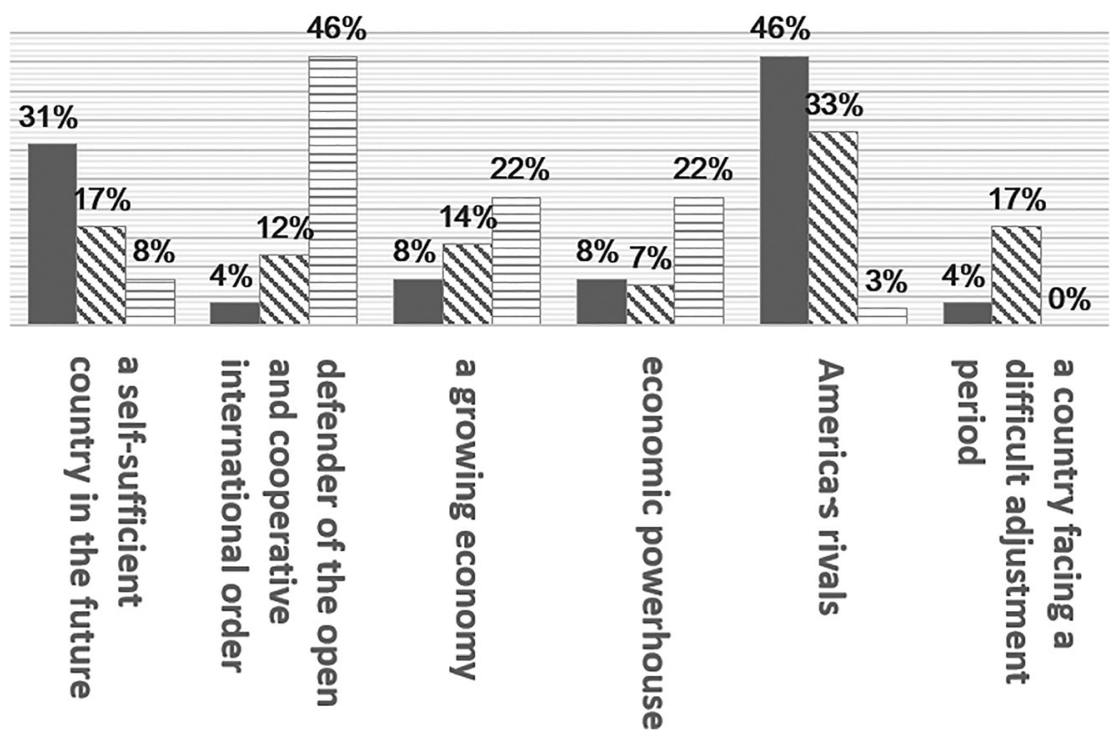

Figure 9: Analysis of the identity narratives.

Table 5: Cross tabulations and chi-square test between media type and identity narrative.

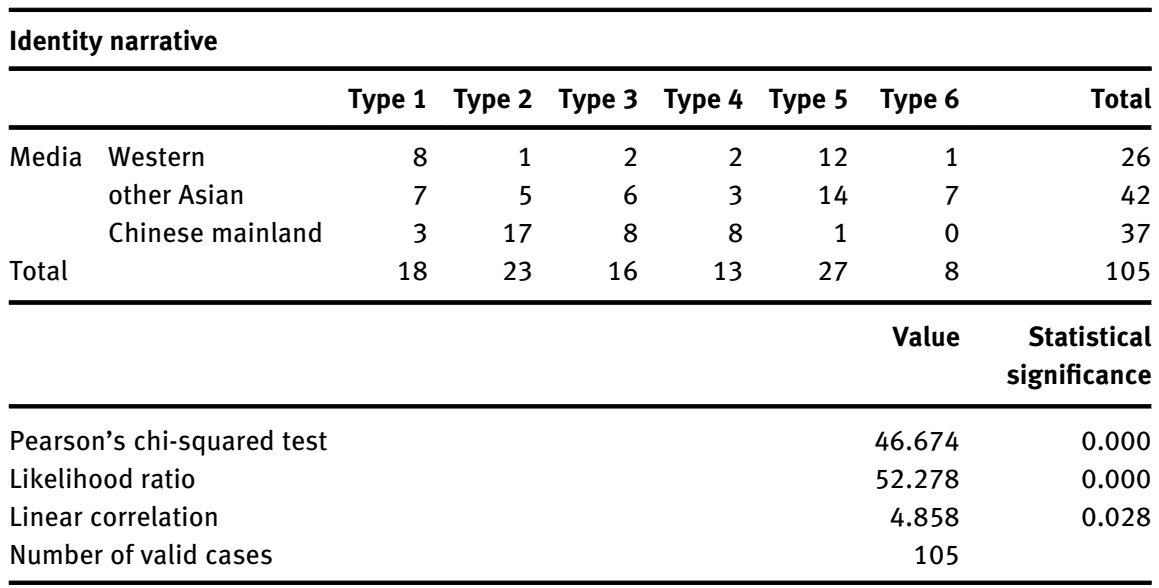

Type 1 - a self-sufficient country in the future; Type 2 - defender of the open and cooperative international order; Type 3 - a growing economy; Type 4 - economic powerhouse; Type 5 - America's rivals; Type 6 - a country facing a difficult adjustment period. 
As shown in Figure 9, from the level of the identity narrative, there are many differences among the three categories of media. $46 \%$ of the Chinese mainland media coverage defines China as a defender of an open and cooperative international order notes that the "new development pattern" means "further opening of the Chinese economy to the world and deeper cooperation between China and other countries in the field of economic development” (Chen, 2021) and the country would further promote international cooperation and help the global economic recovery by “deeper digging China's super-large market, along with continuing opening” (Xinhua, 2020).

$46 \%$ of the Western media and $33 \%$ of the rest Asian media coverage describe China as a competitor to the United States in their identity narratives. In such circumstances, Western media believe that China's "new development pattern" is to counter US sanctions on Chinese technology leaders (Mitchell \& Sun, 2020).

\section{Conclusion and Transcultural Implications}

With the evolution of communication technology and media industry, news media are playing an increasingly important role in international relations. In the process of transnational communication, public diplomacy and national brand building, media narratives have attracted much scholarly attention (Melissen, 2005). Global media has become the battleground of various strategic narrative games in international transcultural politics. By covering news stories, media strategic narratives help political actors to guide public opinions, and to help audiences in different cultures to interpret other political actors' propositions.

Applying a strategic narrative analytical framework, this study observes the policy, system and identity narratives of the "new development pattern" in the global media coverage. Descriptive and statistic data are retrieved to depict the differences and similarities of news reports from media outlets in Chinese mainland, the other Asian countries and regions, and the West. Interpretation, subject, mode, intention, and situation of the strategic narratives are discussed. The study concludes that media organizations in the different regions have their respective narrative characteristics, which can be summarized as a multi-mode strategic narrative pattern for the economic policy communication.

The study finds that the Western media mainly portray the "new development pattern" as a political propaganda and as China's confrontational policy against the U.S. Although Chinese media have made considerable efforts in promoting the "new development pattern" as an economic, opening and cooperative policy, there are still a large number of Western media coverage presenting the "new 
development pattern” as a policy merely benefiting China's own development. This incongruity in media interpretation creates challenges and implications.

As proposed by Castells (2009), strategic narratives can help to achieve goals in international relation by offering an approach of how the relation is built through communication. Therefore, while advocating the "new development pattern" strategy, Chinese media need to adopt strategic narratives in a more proactive approach and to share and raise voices in the global community.

Meanwhile, in a sophisticated global context featured by controversies, multiplex negotiations and cooperation, Chinese media need to better understand the target market and audiences. Media narratives are the key verbal process that affect the perception of people. For the policy issues, global media in culturally dissimilar countries/regions may interpret differently because of the different cultural normative context, so knowledge and skills in transcultural communication are required to understand the context of communication and to improve the quality of media narratives.

In addition, studies and practices in transcultural communication may help to promote the interaction between countries and regions with different cultures. The current study finds that media from the culturally close countries/regions portray China's economic policy with more similarities. Whilst media from the West and the East? Tend to create tensions while covering policy issues, even if those policies are in the interests of global development.

Therefore, in this vein, for the communication of the "new development pattern", Chinese media should, on the one hand, firmly hold China's own position, and on the other hand, learn from the local media to transcend the cultural boundaries. Chinese media may approach global audiences in a more proactive way, by setting up online and offline platforms and by collaborating with the local media. At the same time, they should also take into consideration the cultural differences and rationales in global communication.

The call to form a "new development pattern" is a strategic decision made in accordance with changes in the new historic era. In the "new development pattern", the profound integration of China's economy into the global economic and trade system forms an important part, and fostering an open cultural environment that facilitates cooperation and exchanges between China and other countries is also a major goal. So, while promoting the strategy of the "new development pattern" to the global society, transcultural communication plays a significant role. It is essential to understand how media with diverse cultural backgrounds cover the "new development pattern" and how they narrate China's economic development in the global community.

The current study presents a starting point to explore the strategic narratives and the transcultural communication implications. Based on comparative analysis 
among different media, the study suggests that media differ significantly in narrating the "new development pattern", and there also exist some distortions and misinterpretations in the international media coverage. Therefore, we need to understand the multi-mode narratives of China's economic policy communication, and we also need to firmly hold our position and to advocate China's development policies with new insights of transcultural communication.

\section{Limitations and Prospects}

Strategic narratives can be analyzed in a consecutive path consisting of: 1) the formation of the strategy; 2) the projection of the narratives by the media; and 3) the reception of the users (Miskimmon et al., 2013). Constrained by time and resources, instead of looking into the formation of the strategy, the present study only focuses on the projection of the narratives. With more media attention paid to China's economic development and policies, it is possible to further observe the process of the formation of the narrative strategies on the basis of new and abundant empirical data.

As noted by previous literatures (cf. Miskimmon et al., 2017), although studies of international relations and transcultural communication are conceptually strong, they focus on the constructivist approaches rather than the frameworks and methods that can effectively interpret the phenomenon. This essay has made an effort to interpret the media coverage phenomenon with a theoretical framework of strategic narrative and a joint method of qualitative and quantitative study; implications for transcultural communication are also discussed. However, the essay leaves issues of transcultural communication practices unaddressed in the current form. Therefore, future studies may further explore the implementation of the "new development pattern", observing rules and norms in the communication practices, so as to strive for adequacy in conceptual knowledge as well as a comprehensive understanding of transcultural communication practices.

\section{References}

Arno, A., \& Dissanayake, W. (2019). The news media in national and international conflict. New York: Routledge.

Baker, W. (2018). Transcultural communication and English as a lingua franca: New perspectives on language, culture and intercultural communication. In International Conference of English as a Lingua Franca (ELF11), 4-7 July 2018, Presentation. London, UK: King’s College London.

Buckley, C. (2020). Guide to China's dual circulation economy. The New York Times. Retrieved from https://www.nytimes.com/2020/09/07/business/china-xi-economy.html.

Castells, M. (2009). Communication power. Oxford: Oxford University Press. 
CGTN. (2020). China's dual circulation an active choice and long-term strategy. Retrieved from https://news.cgtn.com/news/2020-10-30/China-s-dual-circulation-an-active-choice-andlong-term-strategy-V0kW26SOu4/index.html.

CGTN. (2021). China will further open up to world economy under 'dual circulation' economic pattern. Retrieved from https://news.cgtn.com/news/2021-03-11/China-will-further-openup-under-dual-circulation-strategy-YxXtZD1EMU/index.html.

Chen, J. (2021). China's 'dual circulation' will bring prosperity to the world. CGTN. Retrieved from https://news.cgtn.com/news/2021-03-06/China-s-dual-circulation-will-bring-prosperitytothe-world-YpgAM6TYM8/index.html.

Cheng, E. (2020). How China is preparing its economy for a future where the U.S. isn't the center of global demand. CNBC. Retrieved from https://www.cnbc.com/2020/09/01/dualcirculationhow-china-is-preparing-for-a-new-role-in-international-trade.html?\&qsearchterm=dual\% 20circulation\%20china.

De Franco, C. (2012). Media power and the transformation of war. Basingstoke: Palgrave Macmillan.

De Graaf, B., Dimitriu, G., \& Ringsmose, J. (2015). Strategic narratives, public opinion and war: Winning domestic support for the Afghan war. London and New York: Routledge.

Freedman, L. (2006). Networks, culture and narratives. The Adelphi Papers, 45(379), 11-26.

Gilboa, E. (2005). The CNN effect: The search for a communication theory of international relations. Political Communication, 22(1), 27-44.

Glover, J., \& Friedman, H. L. (2015). Realizing cultural differences. Washington: American Psychological Association.

Guppy, D., \& Xu, S. (2020). Guide to China's dual circulation economy. CGTN. Retrieved from https://news.cgtn.com/news/2020-10-25/Guide-to-China-s-dual-circulation-economyUS8jtau4h2/index.html.

Hall, E. T. (1959). The silent language. New York: Anchor Books.

Hellman, M., \& Wagnsson, C. (2013). New media and the war in Afghanistan: The significance of blogging for the Swedish strategic narrative. New Media \& Society, 17(1), 6-23.

Ishii, S., Klopf, D.W., \& Cooke, P. (2003). Our locus in the universe: Worldview and intercultural communication. In L. A. Samovar \& R. E. Porter (Eds.), Intercultural communication: A reader (10th ed., pp. 28-35). Belmont, CA: Wadsworth.

Korybko, A. (2020). China's dual circulation paradigm has nothing to do with 'decoupling'. CGTN. Retrieved from https://news.cgtn.com/news/2020-12-15/China-s-dual-circulationparadigmhas-nothing-to-do-with-decoupling-Wfgqpt/Zao/index.html.

Kramsch, C. (2011). Language and culture. Routledge.

Lifintsev, D. S., \& Canhavilhas, J. (2017). Cross-cultural management: Obstacles for effective cooperation in multicultural environment. Scientific Bulletin of Polissia, 2(10), 195-202.

McCombs, M. E., \& Shaw, D. L. (1972). The agenda-setting function of mass media. Public Opinion Quarterly, 36(2), 176-187.

Melissen, J. (2005). Wielding soft power: The new public diplomacy. Netherlands: Netherlands Institute of International Relations Clingendael.

Miskimmon, A., O’loughlin, B., \& Roselle, L. (2013). Strategic narratives: Communication power and the new world order. London and New York: Routledge.

Miskimmon, A., O’loughlin, B., \& Roselle, L. (2017). Forging the world: Strategic narratives and international relations. Michigan: University of Michigan Press. 
Mitchell, T., \& Sun, Y. (2020). Washington looms large over drafting of China's next five-year plan. Financial Times. Retrieved from https://www.ft.com/content/205a600d-462f-47a6-a242a606b949ce91.

Nye Jr., J. S. (2008). Public diplomacy and soft power. The Annals of the American Academy of Political and Social Science, 616(1), 94-109.

Pennycook, A. (2006). Global Englishes and transcultural flows. London and New York: Routledge. Roselle, L., Miskimmon, A., \& O’loughlin, B. (2014). Strategic narrative: A new meansto understand soft power. Media, War \& Conflict 7(1), 70-84.

Samovar, L. A., \& Porter, R. E. (2007). Intercultural communication: A reader. Shanghai: Shanghai Foreign Language Education Press.

Singer, M. R. (1987). Intercultural communication: A perceptual approach. Hoboken: Prentice Hall.

Teng, T. (2020). Consumption expansion holds key to making dual-circulation effective. China Daily. Retrieved from http://global.chinadaily.com.cn/a/202012/14/WS5fd6c155a31024ad0ba9b979. html.

Tharoor, I. (2020). Xi's China is preparing for a new world order. Washington Post. Retrieved from https://www.washingtonpost.com/world/2020/12/15/xi-china-new-order-trump/.

Todorov, T., \& Weinstein, A. (1969). Structural analysis of narrative. Novel: A Forum on Fiction, 3(1), 70-76.

Triandis, H. C. (2000). Culture and conflict. International Journal of Psychology, 35(2), 145-152.

Wei, T. D. (2021). Singapore can play key role in China's 'dual circulation' economy: Vivian Balakrishnan. Straits Times. Retrieved from https://www.straitstimes.com/asia/east-asia/ singapore-can-play-key-role-in-chinas-dual-circulation-economy-vivian-balakrishnan.

Welsch, W. (1999). Transculturality: The puzzling form of cultures today. Spaces of Culture: City, Nation, World, 13(7), 194-213.

Wendt, A. (1999). Social theory of international politics. Cambridge: Cambridge University Press. Xinhua. (2020). Understanding "dual circulation" and what it means for world. Retrieved from http://www.xinhuanet.com/english/2020-09/05/c_139345700.htm.

Yao, K. (2020). Reform hopes rise as China focuses on inward economic shift. Reuters. Retrieved from https://www.reuters.com/article/idUSKBN2610F9. 